\title{
New coral community on a breakwater in Thailand
}

Received: 29 September 2008/ Accepted: 25 November 2008/Published online: 17 December 2008

(C) Springer-Verlag 2008

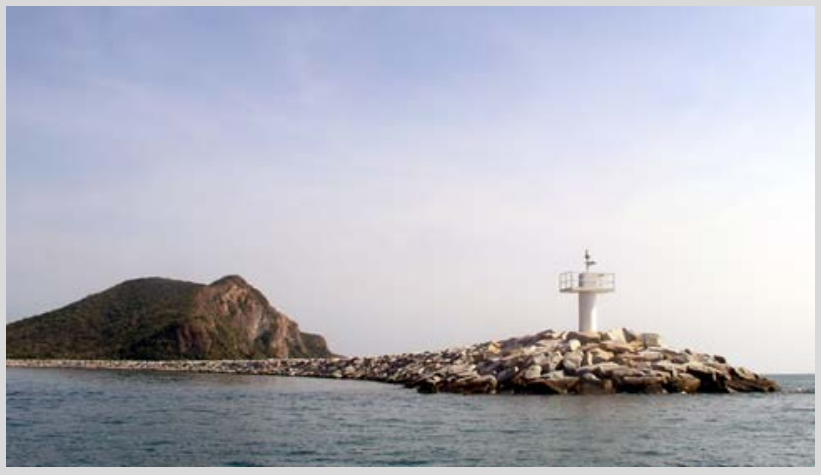

Fig. 1 The $800 \mathrm{~m}$ long breakwater located at the Royal Thai Navy, Sattahip, Chonburi Province

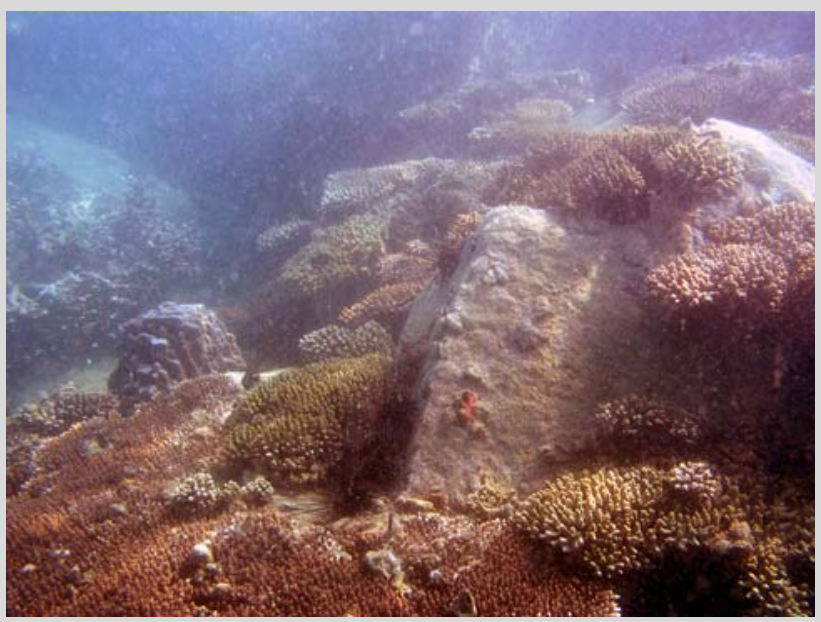

Fig. 2 New coral community on the breakwater
In 1995, an $800 \mathrm{~m}$ long breakwater, composed of granite rocks (sizes between 1 and $8 \mathrm{~m}^{3}$ ), was constructed to create a new military harbor at the Royal Thai Navy, Sattahip, Chonburi Province, Thailand (Fig. 1). Prior to construction, most corals were transplanted from the area to other islands, which were located $\sim 1.2 \mathrm{~km}$ southwest of the breakwater.

In 2002-2007, surveys of coral diversity were conducted at the breakwater and islands around the harbor areas. Line transects surveys showed that coral cover ranged between $40 \%$ and $70 \%$ (Fig. 2). Surprisingly, diversity of corals on the breakwater was as high as those at the surrounding islands. A total of 67 species of scleractinian corals and 9 genera of gorgonians were found. Acropora was the most dominant genus. In contrast, fish surveys revealed that only 17 species were found in the breakwater area, compared to more than 32 fish species occurring at natural reefs in islands nearby. High coral diversity has also been found on breakwaters in other countries (Omori and Fujiwara 2004; Wen et al. 2007). To determine the possible causes of high coral diversity at this breakwater, sources of coral larvae and direction of currents were investigated. The results from a simulation model (two-dimensional hydrodynamic model) of trajectory drogue indicated that during periods of coral spawning, the current flowed out of Ko Khram (located $1.2 \mathrm{~km}$ northwest of the breakwater) to the breakwater. The current patterns and the larval drift pattern suggest that coral larvae dispersed from Ko Khram to the breakwater and that colonization of these coral larvae formed the new coral community in the area.

Spawning of Acropora spp. was first observed in February 2004 at the breakwater. Subsequently, spawning of corals at the breakwater has occurred each year from January to March.

Acknowledgements We would like to thank Lalita Putchim, Se Songploy, and Pataporn Kuanui for field assistance. This project was supported by Plant Genetic Conservation Project under the Royal Initiative of Her Royal Highness Princess Maha Chakri Sirindhorn, Royal Thai Navy, Thailand Research Fund (TRG4980006), TRF/ BIOTEC Special Program for Biodiversity Research and Training Grant T_348009, Office of Commission for Higher Education-CU Graduate Thesis Grant, and the 90th Anniversary of Chulalongkorn University Fund (Ratchadaphiseksomphot Endowment Fund).

\section{References}

Omori M, Fujiwara S (2004) Manual for restoration and remediation of coral reefs. Nature Conservation Bureau, Ministry of the Environment, Japan

Wen KC, Hsu CM, Chen KS, Liao MH, Chen CP, Chen CA (2007) Unexpected coral diversity on the breakwater: potential refuges for depleting coral reefs. Coral Reefs 26:127

V. Viyakarn $(\bowtie) \cdot$ S. Chavanich $\cdot$ C. Raksasab · T. Loyjiw

Department of Marine Science, Faculty of Science, Chulalongkorn University, Bangkok 10330, Thailand e-mail: vvoranop@chula.ac.th

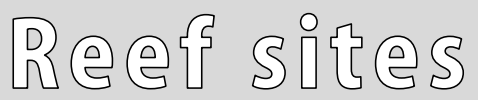

Coral Reefs (2009) 28:427

DOI $10.1007 / \mathrm{s} 00338-008-0453-9$ 